\title{
Enhancement in Electrical and Thermal Performance of High Temperature Vulcanized Silicone Rubber Composites for Outdoor Insulating Applications
}

\author{
Sohrab Azizi ${ }^{1 *}$, Gelareh Momen², Claudiane Ouellet-Plamondon ${ }^{1,}$ \\ Eric David ${ }^{1}$
}

\author{
${ }^{1}$ École de Technologie Supérieure (Université du Québec), 1100 Notre Dame St. W, \\ H3C 1K3, Montréal, QC, Canada \\ ${ }^{2}$ Université du Québec à Chicoutimi (UQAC), 555 Boulevard de l'Université, Chicoutimi, QC G7H \\ 2B1, Canada
}

\begin{abstract}
High temperature vulcanized silicone rubber composites are highly desirable as outdoor insulating materials due to their immense thermal and electrical performance. The aim of this work is to study the role of cocombined fillers (modified fumed silica (MFS), titanium dioxide $\left(\mathrm{TiO}_{2}\right)$, with graphene $(\mathrm{G})$ ) on electrical and thermal properties of silicone rubber (S) composites. The dielectric response of S/MFS_10 phr and $\mathrm{S} / \mathrm{TiO}_{2} 20$ composites tailored with $2 \mathrm{phr} \mathrm{G}$ was characterized by broadband dielectric spectroscopy. The hybrid filler/composites were found to show higher thermal stability when $2 \mathrm{phr} G$ was added. In addition, a low quantity of $\mathrm{G}$ filler was found to slightly increase the $\mathrm{AC}$ dielectric breakdown strength of the S/MFS_10 and S/TiO $2 \_20$, where an improvement of 3 and $5 \%$ was found, respectively. Several steps were observed in the thermal decomposition of the $\mathrm{S}$ rubber composites by Thermogravimetric analysis-Fourier transform infrared spectroscopy. Our findings revealed great potentials for fabricating hybrid-filler/silicone rubber composites with enhanced electrical and thermal properties for outdoor insulating applications.
\end{abstract}

Keywords: Silicone rubber, inorganic filler, thermal stability, dielectric constant, graphene, outdoor insulating.

\footnotetext{
* Correspondence to: Sohrab Azizi, E-mail: sohrab.azizi.1@ens.etsmtl.ca

Department of construction engineering, École de technologie supérieure (ÉTS), Université du Québec, 1100 Notre-Dame St W, Montréal, QC H3C 1K3 Canada.
} 


\section{Introduction}

Silicone rubber composites have received significant attention for the use in high-voltage outdoor insulating applications due to their remarkable properties such as long durability, low maintenance cost, easy installation and a broad range of regional applications ${ }^{1-4}$. Silicone rubber is known as a synthesis polymer with significant weatherability, remarkable resistance to ultraviolet (UV) degradation and noticeable resistance to oxidation ${ }^{3,5-7}$. The low surface energy of silicone rubber gives suitable hydrophobicity for outdoor insulating applications ${ }^{8}$. This causes lower contamination deposition on its surface and higher water repellency ${ }^{9,10}$. Loading of inorganic fillers such as silica and titanium dioxide can increase thermal and electrical performance of outdoor insulating materials ${ }^{3}$. In addition, higher mechanical properties may be obtained ${ }^{9,11-14}$. For example, incorporating aluminum hydroxide (ATH) and silica in silicone rubber composites was found to increase the tensile strength, dielectric breakdown strength and thermal stability of the ATH/silicone and silica/silicone rubber composites ${ }^{9,15-21}$. The combination of micron-aluminum nitride and nano- $\mathrm{SiO}_{2}$ fillers with silicone rubber resulted in higher thermal stability, whereas a lower dielectric permittivity was achieved ${ }^{19}$. Composites with micro-sized $\mathrm{Si}_{3} \mathrm{~N}_{4}$ and nano-sized $\mathrm{Al}_{2} \mathrm{O}_{3}$ fillers showed remarkable thermal conductivity $(1.62 \mathrm{~W} / \mathrm{m} . \mathrm{K})$ with relatively low dielectric constant, where the nano-sized filler was embedded in gaps between the micro-sized fillers, forming a continuous thermally conductive composite ${ }^{22}$. The inclusion of hollow silica spheres within room temperature vulcanized silicone rubber showed a considerable increase in dielectric breakdown strength when $5 \mathrm{wt} \%$ of the filler was added ${ }^{23}$. Modified inorganic fillers were also used in order to enhance the interfacial adhesion, particle dispersion in which leads an increase in electrical and thermal performance of the composite ${ }^{24-26}$. For example, chemically modified $\mathrm{TiO}_{2} /$ silicone rubber composite was found to show a higher dielectric breakdown strength than that of non-modified ${ }^{20}$. Graphene filler with the extraordinary physical, electrical and thermal properties among all of the materials ${ }^{27,28}$ was utilized in silicone rubber composites and the outcomes revealed a noticeable increase in tensile strength and thermal stability ${ }^{29}$.

Outdoor insulating composites such as silicone rubber-based composites are expected to endure a long time in oxidative atmospheres ${ }^{30}$, thus using UV protective fillers such as carbon black or graphene can be suggested as suitable filler against UV protection ${ }^{2,18}$. On the other hand, graphene, as earlier mentioned, can increase the electrical, thermal and mechanical performance of silicone rubber composite. $\mathrm{TiO}_{2}$ is known as a self-cleaning inclusion ${ }^{31}$ that can be utilized in silicone rubber composites to avoid destructive electrical incidents caused by surface contamination ${ }^{18,32}$. In addition, higher thermal stability and dielectric constant were reported for the tailored silicone rubber composites with $\mathrm{TiO}_{2}$ filler ${ }^{33,34}$. Increase in the thermal stability of $\mathrm{TiO}_{2}$ /silicone rubber composites prevents thermal degradation caused by the dry arc. Moreover, $\mathrm{TiO}_{2}$ can increase dielectric constant in silicone rubber insulators to prevent any charge leakage 
or flashover along the insulator ${ }^{35}$. Silica-based fillers play a vital role in suppressing destructive thermal degradation in silicone rubber composite thanks to superior physical reinforcement effect ${ }^{36}$. Therefore, MFS and $\mathrm{TiO}_{2}$ fillers with remarkable electrical, thermal, mechanical and weathering properties as well as the versatile properties of graphene promoted us to design a co-combined rubber composite including inorganic fillers and graphene. At low filler content of graphene, an increase in the dielectric constant of silicone rubber composite was reported ${ }^{37,38}$, whereas a percolation threshold can be achieved at high filler concentration. Therefore, a low content of graphene filler ( $2 \mathrm{phr}$ ) was targeted to be loaded in the composites. According to the studies done by now, the effect of inorganic fillers on the thermal and electrical performance of silicone rubber composites was investigated, but no research on silicone-based composites containing both inorganic fillers and graphene has been reported. Thus, in this study, electrical and thermal performance of silicone rubber composites with two inorganic fillers such as modified fumed silica and titanium dioxide with and without graphene filler are investigated.

\section{Materials, compounding, and characterization}

\subsection{Materials}

Polydimethylsiloxane diol (silicone rubber) commercially labeled as Elastosil @ R 401/60 with an apparent density of $1.15 \mathrm{~g} / \mathrm{cm}^{3}$ at $20{ }^{\circ} \mathrm{C}$ was supplied by Wacker. Titanium (IV) dioxide $\left(\mathrm{TiO}_{2}\right.$ ), anatase grade, was purchased from Sigma-Aldrich. Modified fumed silica (MFS) (silica treated with a silanamine coupling agent) was provided by Cabot (USA) under the trade name of CAB-O-SIL @ TS-530. Graphene $\left(\right.$ Grapheneblack $^{\mathrm{TM}} 3 \mathrm{X}$ ) with a primary particle size of $1-2 \mu \mathrm{m}$, an agglomerate particle size of D50 = $38 \mu \mathrm{m}$ and a bulk density of $0.18 \mathrm{~g} / \mathrm{cm}^{3}$ of was provided by Nanoxplore. Dicumyl peroxide (DCP) was supplied by Sigma-Aldrich. All materials were used as received.

\subsection{Sample preparation}

Several silicone rubber composites were prepared by mechanical mixing using a Haake internal mixer (Rheomix OS). 20 parts per hundred rubber (phr) of $\mathrm{TiO}_{2}$ was compounded with silicone rubber and the amount of MFS was limited to $10 \mathrm{phr}$ due to high shear viscosity limitation during the fabrication. The compounding was carried out for 10 min mixing time with a screw speed of $10 \mathrm{rpm}$ at $70{ }^{\circ} \mathrm{C}$. Several batches of composites were selected, as listed in Table I. All prepared composites were then cured at 165 ${ }^{\circ} \mathrm{C}$ and under a $10 \mathrm{MPa}$ load for $10 \mathrm{~min}$, using a hydraulic hot press (Accudyne Engineering \& Equipment Company, Los Angles, USA). Eventually, the cured composites were gradually cooled down to room temperature. 
Table I: Silicone rubber composites formulations.

\begin{tabular}{lccccc}
\hline \multicolumn{1}{c}{ Component } & $\mathrm{S}(\mathrm{phr})$ & $\mathrm{MFS}(\mathrm{phr})$ & $\mathrm{TiO}_{2}(\mathrm{phr})$ & Graphene $(\mathrm{phr})$ & $\mathrm{DCP}(\mathrm{phr})$ \\
\hline $\mathrm{S}$ & 100 & - & - & - & 0.7 \\
$\mathrm{~S} / \mathrm{MFS} \_10$ & 100 & 10 & - & - & 0.7 \\
$\mathrm{~S} / \mathrm{MFS} \_10 / \mathrm{G} 2$ & 100 & 10 & - & 2 & 0.7 \\
$\mathrm{~S}_{\mathrm{TiO}} 220$ & 100 & - & 20 & - & 0.7 \\
$\mathrm{~S}_{\text {TiO }}$ 220/G2 & 100 & - & 20 & 2 & 0.7 \\
\hline
\end{tabular}

\subsection{Characterization and measurements}

\subsubsection{Granulometry}

The particle sizes of the fillers were measured using a laser particle size analyzer (Mastersizer 3000) by dispersing particles in dispersant at $3000 \mathrm{rpm}$ of agitation speed.

\subsubsection{Scanning electron microscopy (SEM)}

The morphology of the vulcanized composites was investigated using high-resolution scan electron microscope (Hitachi, SU-8230 FE-SEM, Japan). For each SEM imaging, a cryogenically fractured by microtome cross-sectional sample was prepared by immersing the test specimens in liquid nitrogen. The cryofractured samples were subsequently coated by $2 \mathrm{~nm}$ of platinum in a vacuumed chamber using a turbopumped sputter coater/carbon coater (Q150T, Guelph, Canada).

\subsubsection{Dielectric spectroscopy}

The dielectric response of the composites was measured using a broadband dielectric spectrometer (Novocontrol). Measurements were carried out at room temperature and over a wide range of frequencies varying from $10^{-1}$ to $10^{5} \mathrm{~Hz}$. For each measurement, a disk-shaped sample with a thickness of $\sim 2 \mathrm{~mm}$ and a diameter of $30 \mathrm{~mm}$ was placed between the two solid electrodes, forming a plane-plane capacitor, and the applied AC voltage was 3 Vrms (root mean square of the voltage).

\subsubsection{Breakdown strength measurement}

The electric breakdown strength of the $\mathrm{S}$ composite rubbers was evaluated using Baur electric breakdown tester. Measurement was conducted according to ASTM D149-09(2013) with 10 disk samples with a diameter of $10 \mathrm{~mm}$ and a thickness of 2-2.5 mm. The samples were placed between spherical electrodes of $4 \mathrm{~mm}$ of diameter and were subjected to $\mathrm{AC}$ electric field with a rising rate of $0.5 \mathrm{kV} / \mathrm{s}$ until failure. The measurements were performed in a mineral oil surrounding medium in order to avoid flashovers. 


\subsubsection{Fourier-transform infrared spectroscopy (FTIR)}

Interfacial chemical interactions between the medium rubber, fillers as well as the vulcanizing agent were investigated using FTIR measurements in the absorbance mode over wavenumbers from 400 to $4000 \mathrm{~cm}^{-1}$ with PerkinElmer FTIR Spectrometer Spectrum II.

\subsubsection{Thermogravimetric analysis- FTIR}

A TGA-FTIR instrument consisting of a thermogravimetric analyzer (STA 8000 instrument (PerkinElmer) linked to a Spectrum II (PerkinElmer) was used to investigate the thermal properties. TGA measurements were performed on test specimens $\sim 20$ to $30 \mathrm{mg}$, under a $70 \mathrm{ml}$ of nitrogen gas flow. All samples were heated from 50 to $800{ }^{\circ} \mathrm{C}$ with a rate of $30^{\circ} \mathrm{C} / \mathrm{min}$ and then the samples were kept under air atmosphere for $2 \mathrm{~min}$. The released elements from the TGA's furnace chamber were passed through a tube to each the FTIR analyzer. To avoid any condensation of the elements along the connecting line, the tube's temperature was set at $230{ }^{\circ} \mathrm{C}$.

\subsubsection{Hydrophobicity measurement}

The hydrophobicity of the test specimens was measured by VCA optima contact angle testers. Prior to the measurement, the surface of the test specimen was carefully washed with isopropanol and dried with instrument air. A droplet of deionized ultra-pure water with a volume of $5 \mu$, deposited on the surface of each sample. An average of 5 droplets contact angle was reported for each sample.

\subsubsection{Thermal conductivity measurement}

The thermal conductivity of silicone rubber and its composite was measured by a transient plane source thermal conductivity meter (C-Therm Technologies). Measurement was carried out by sandwiching a diskshaped sample with a diameter of $20 \mathrm{~mm}$ and a thickness of $\sim 2 \mathrm{~mm}$.

\section{Results and discussion}

\subsection{Filler size distribution}

The particle size distribution of the fillers that were used for the composites fabrication can be seen in Fig. 1. A wide range of particle size was observed for all fillers. A bigger particle size of the approximately 20 $\mu \mathrm{m}$ was observed for the MFS and graphene, whereas $\mathrm{TiO}_{2}$ featured smaller particle size in the range of 1 to $10 \mu \mathrm{m}$. A small portion of graphene and $\mathrm{TiO}_{2}$ fillers were found to have a particle size in nanoscale. MFS was found to have particle size only in micron size. 


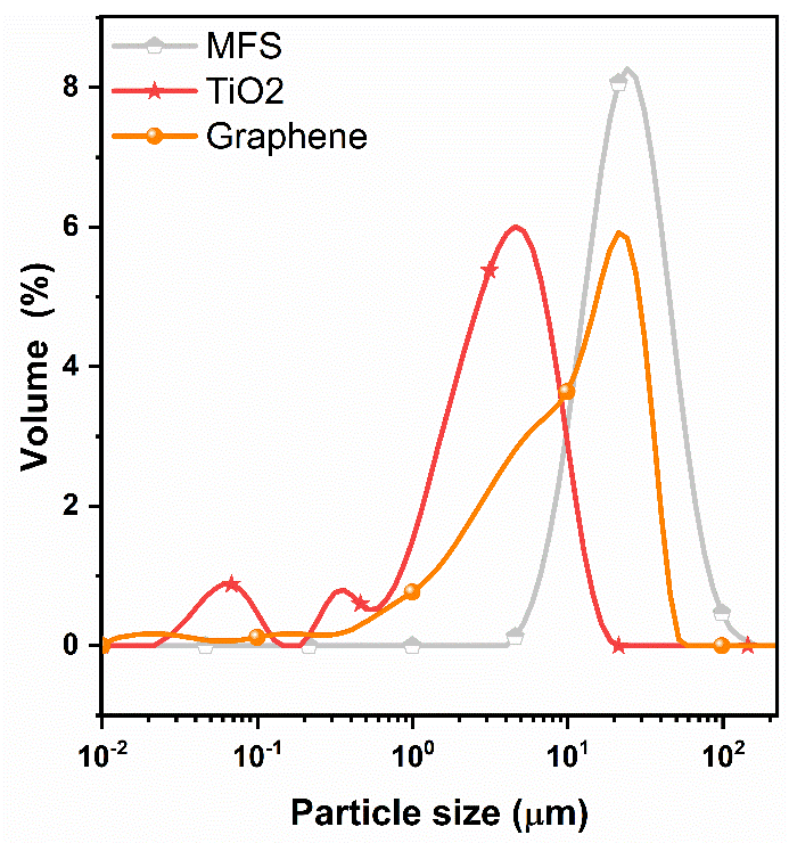

Fig. 1: Distribution of particle size of $\mathrm{MFS}, \mathrm{TiO}_{2}$, and graphene used in this study.

In order to investigate the morphology of the silicone rubber composites, SEM micrographs of the samples were taken and are shown in Fig. 2. SEM micrographs of silicone rubber are illustrated at two different magnifications (Fig. 2a,b). MFS filler incorporated in S rubber was found to disperse uniformly with the expected particle size of $\sim 10-20 \mu \mathrm{m}$ (see Fig. 2c). The good dispersion of the MFS in S rubber matrix can be explained by significant affinity and interfacial compatibility between MFS and S which results in strong interfacial interaction ${ }^{9,16}$. Adding graphene to S/MFS_10 led to aggregate regions in composite structure due to intrinsic agglomeration property of graphene (see Fig. 2d). In fact, comparing the particle size of the graphene in SEM micrographs and granulometry measurements, it can be observed that during composite manufacturing, shear stress restacked graphene layers and formed graphene platelets. The addition of 20 phr $\mathrm{TiO}_{2}$ filler to $\mathrm{S}$ rubber composite resulted in a denser particle dispersion and distribution with a reasonably good homogeneity thanks to interfacial physical interaction between the filler and matrix ${ }^{33}$ (see Fig. 2e). The SEM surface morphology image of $\mathrm{S} / \mathrm{TiO}_{2} \_20 / \mathrm{G} 2$ (see Fig. 2f) displayed a smoother picture with respect to the $\mathrm{S} / \mathrm{TiO}_{2} \_20$, showing a good dispersion of graphene filler within the composite which it might be due to possibly further interaction between the inclusions and the matrix ${ }^{37}$. 


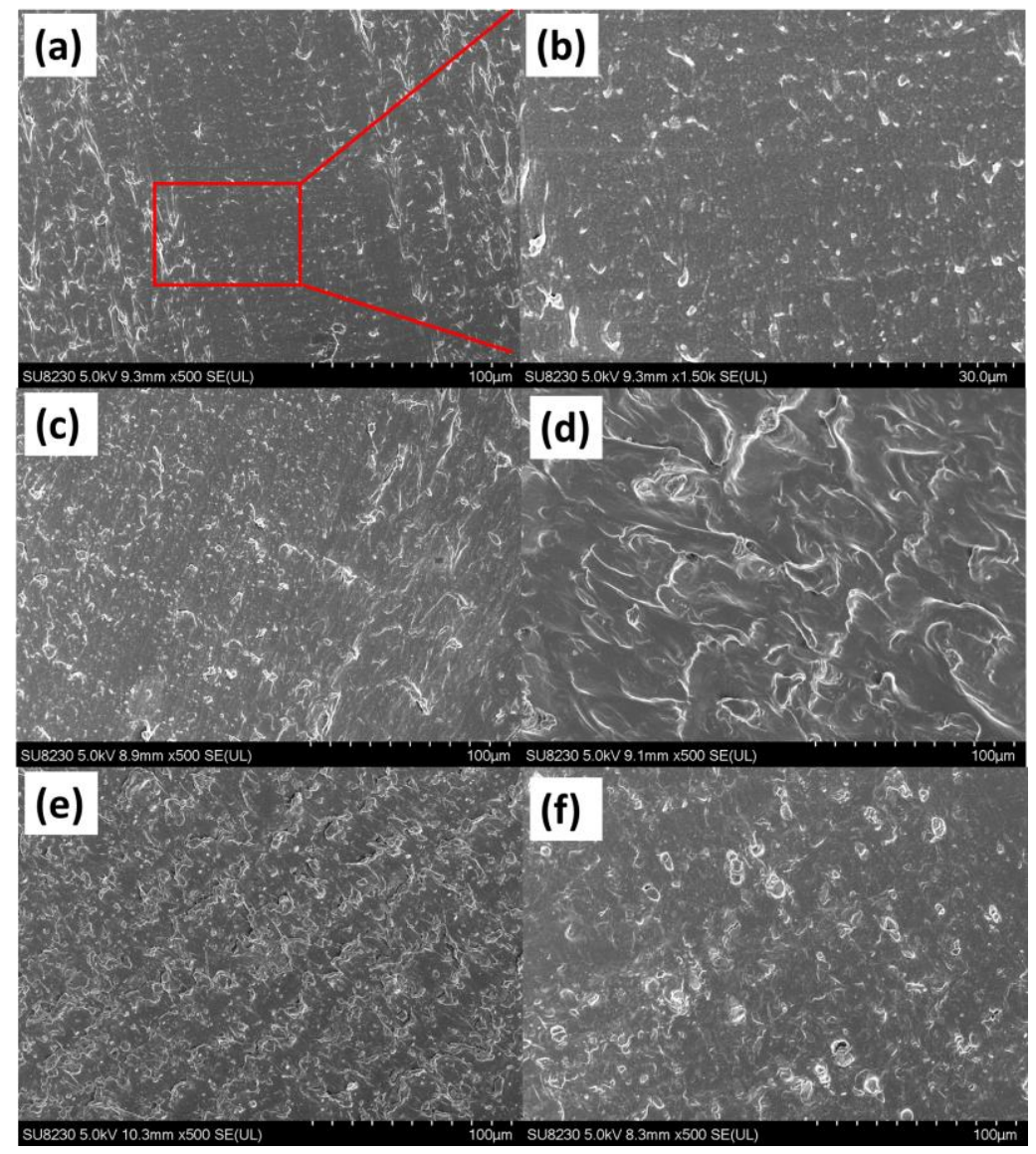

Fig. 2: SEM images of (a and b) S rubber, (c) S/MFS_10, (d) S/MFS_10/G2, (e) S/TiO $2 \_20$ and (f) $\mathrm{S} / \mathrm{TiO}_{2} \_20 / \mathrm{G} 2$.

\subsection{Dielectric spectroscopy}

The frequency-domain dielectric responses of the silicone rubber composites are shown in Fig. 3a and Fig. $3 \mathrm{~b}$ in the form of the real part of the complex (dielectric constant) and the ratio of the imaginary part and the real part $(\tan \delta)$, respectively. Silicone rubber possesses slightly polar groups which result in in weak dipolar relaxation behavior that can hardly be observed at room temperature while it easier to see at lower temperature in the $10^{3}$ to $10^{6}$ frequency range ${ }^{12,22,39}$. The incorporation of $10 \mathrm{phr}$ MFS and $2 \mathrm{phr}$ graphene in silicone rubber led to an increase in dielectric constant of the composites mainly thanks to the higher dielectric constant of the fillers as well as maybe a slightly local interfacial polarization on the surface of the inclusions $3,12,40,41$. Loading of MFS and MFS/G did not result in any significant alteration of the dielectric loss of the composites. The addition of $\mathrm{TiO}_{2}$ to the $\mathrm{S}$ rubber was resulted in a higher dielectric constant due to significant higher permittivity of $\mathrm{TiO}_{2}(\sim 110)$ with respect to the silicone rubber $(3.1){ }^{42}$, as well as a significant charge accumulation at the surface boundaries of the $\mathrm{TiO}_{2}$ particles (interfacial polarization) which can be enhanced by possible moisture absorption by the filler ${ }^{20,43-45}$. Thus, when a 
heterogeneous material is subjected to an electric field of $\Delta V=V 1-V 2$, as seen in Fig. 4, the incorporation of conductive fillers, moisture absorption as well as charge accumulation at the surface boundaries increase the charge carrier along the materials ${ }^{28,46}$.

(a)

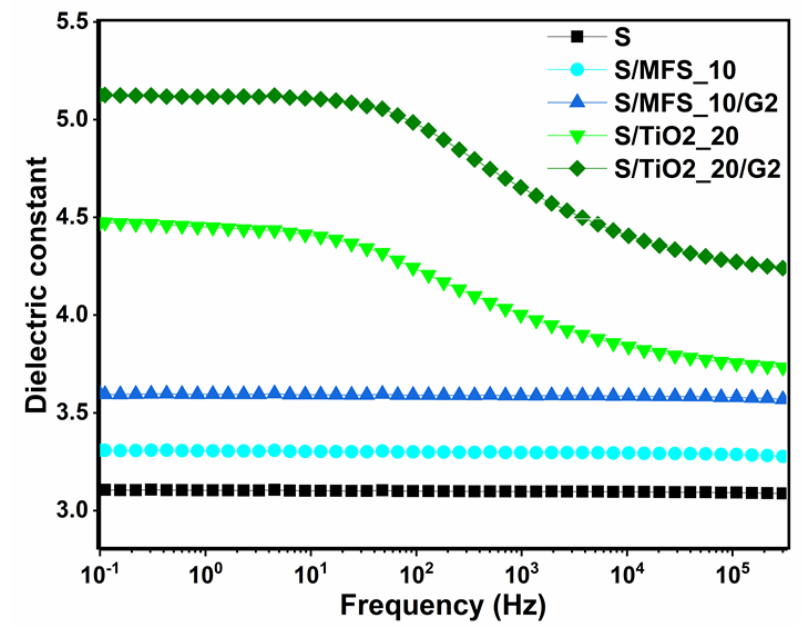

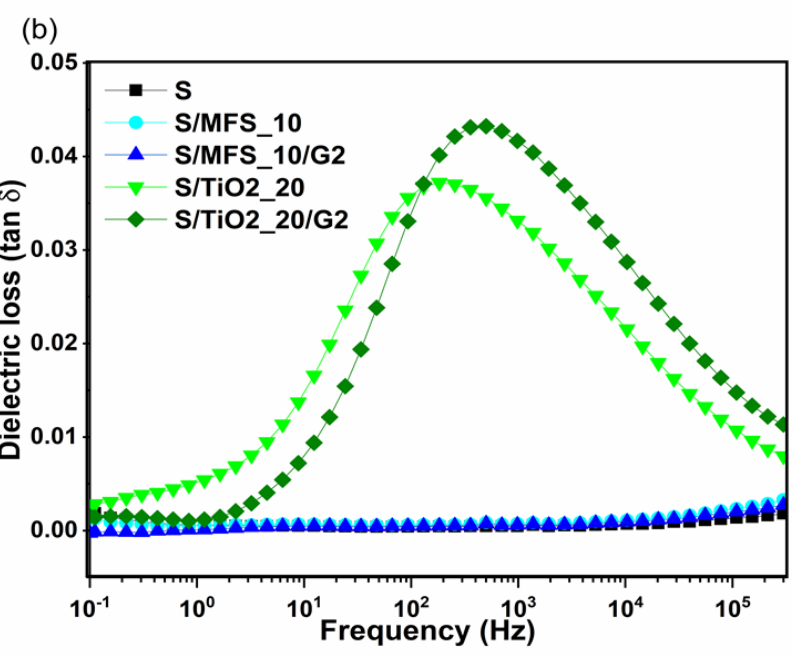

Fig. 3: Dielectric properties of silicone rubber composites (a) dielectric constant and (b) dielectric loss at room temperature.

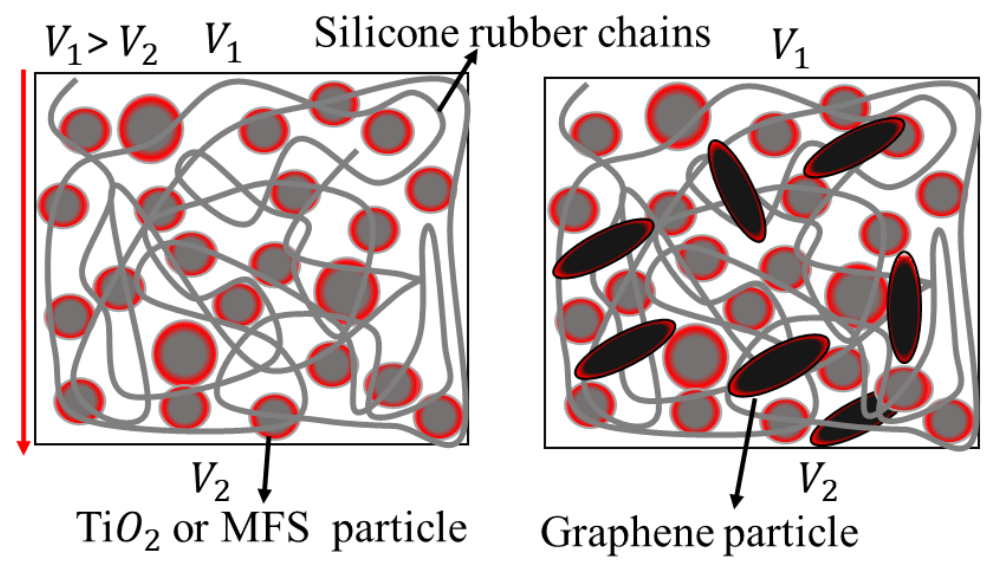

Fig. 4: 2D Schematic of the charge accumulation on the surface of the inclusions with higher electrical conductivity within the silicone rubber composite.

\subsection{AC dielectric breakdown (BD)}

Fig. 5 shows the Weibull distribution plot of the BD strength of the S rubber and its composites with MFS, $\mathrm{TiO}_{2}$ and graphene. The characteristic breakdown strength of $\mathrm{S}$ was found to be $20.3 \mathrm{kV} / \mathrm{mm}$ for 2 to 2.5 mm thick samples, and the addition of $20 \mathrm{phr}$ MFS resulted in a value of $22.9 \mathrm{kV} / \mathrm{mm}$ which is a $12 \%$ improvement in BD strength. This increase in dielectric breakdown strength can be ascribed to the trapping 
of the charge carriers at the interfacial boundaries of the filler and matrix which hinder the electrical treeing 1. The dielectric breakdown in dielectrics can occur when the generated heat inside the material exposed to the electrical field overtakes the dissipated heat leading to a thermal runaway. This phenomenon is known as thermal breakdown and other mechanisms such as electromechanical breakdown as well as partial discharge breakdown can also lead to failure ${ }^{42}$. Loading of 2 phr graphene filler for S/MFS_10 led to further increase $3 \%$ in the characteristic breakdown strength which can be attributed to the intrinsic barrier properties of graphene that limit charge leakage ${ }^{38}$. Compounding of $\mathrm{S}$ rubber with $20 \mathrm{phr}$ content $\mathrm{TiO}_{2}$ filler was also found to increase the dielectric breakdown strength $(22.51 \mathrm{kV} / \mathrm{mm})$, approximately $10 \%$ improvement than that of neat silicone rubber. The higher breakdown strength was due to the fact that highly polar $\mathrm{TiO}_{2}$ particles are prone to create deeper traps fixing eventual space charges and consequently improving the dielectric breakdown strength ${ }^{20}$. Graphene filler at low content ( $2 \mathrm{phr}$ ) also resulted in a further increase in dielectric breakdown strength of $\mathrm{S}_{\mathrm{TiO}} \_20$ where an additional improvement of $5 \%$ was reached. 


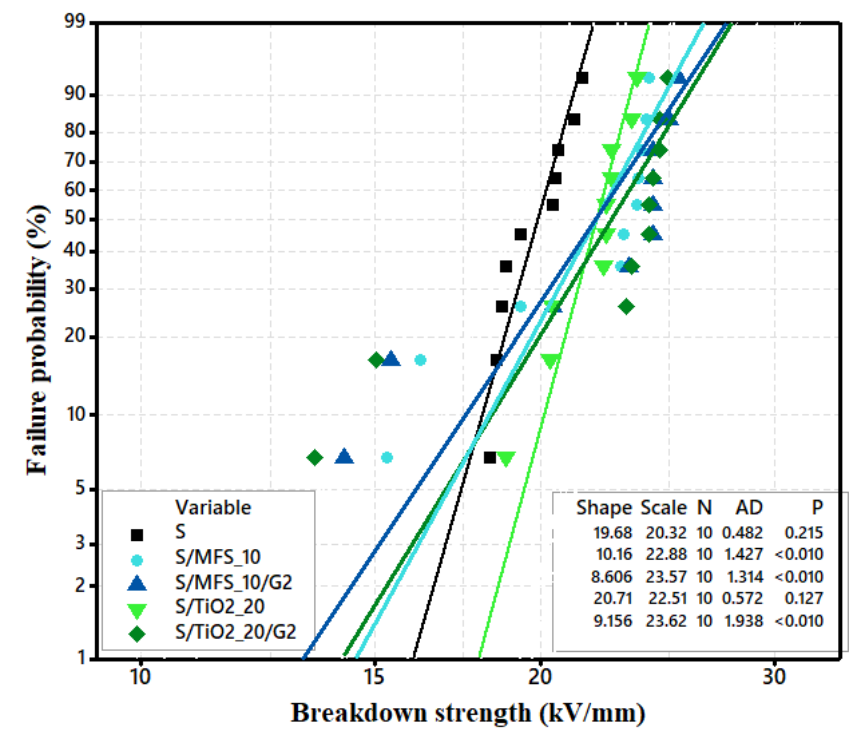

Fig. 5: Electrical breakdown strength of the silicone rubber and silicone rubber composites with MFS, $\mathrm{TiO}_{2}$, and graphene.

\subsection{FTIR spectroscopy}

Fig. 6 shows the FTIR spectra of S rubber composite and pure vulcanized S rubber. At $3013 \mathrm{~cm}^{-1} \mathrm{a}$ characteristic peak was detected which is related to C-H stretching bonds. Another characteristic absorption peak was observed at $1260 \mathrm{~cm}^{-1}$ which is linked to Si-C stretching vibration of methyl side groups ${ }^{47,48}$. The absorption peak at $1070 \mathrm{~cm}^{-1}$ is linked to the Si-O bending vibration existing in Si-O-Si backbone ${ }^{49}$. No significant absorption peak was seen at wavenumbers between 3200 to $3500 \mathrm{~cm}^{-1}$ that confirm the lack of any $-\mathrm{OH}$ bonds in the structure of the composite.

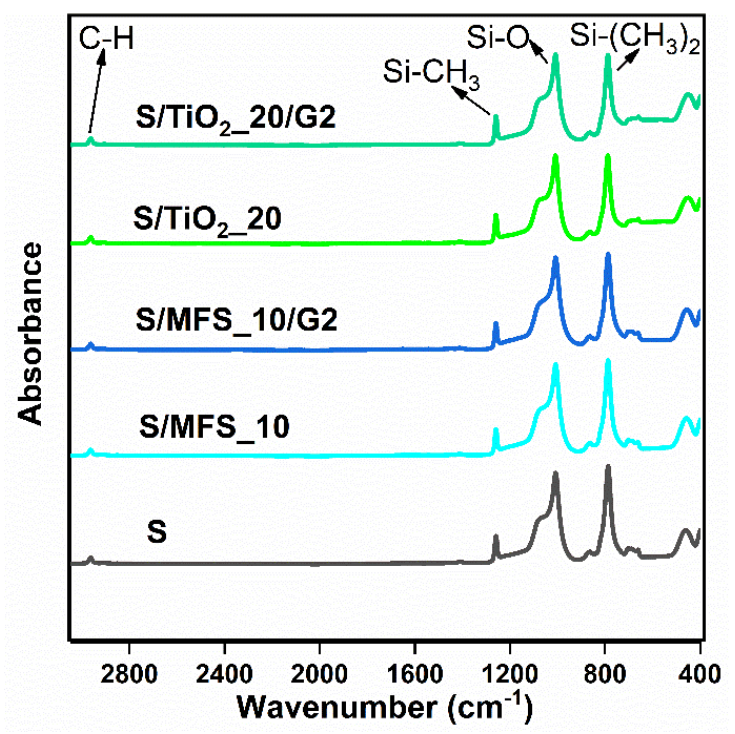

Fig. 6. FTIR spectra of $\mathrm{S}$ rubber and its composites with $\mathrm{MFS}, \mathrm{TiO}_{2}$, and graphene. 


\subsection{Thermogravimetric Analysis}

Thermal properties in high-voltage insulating materials play significant role in their performances. For example, the incidents such as dry band arcing, corona exposure discharge, flashover and UV degradation affect dramatically the material's hydrophobicity, causing progressive destructive phenomenon in silicone rubber insulators. Similarly, thermal aging worsens tracking and surface erosion, which consequently cause electrical failures. Thus, in this section the thermal stability of the test specimens were analyzed by TGA and the thermograms and extracted results are shown in Fig. 7 and Table II, respectively. The addition of MFS, $\mathrm{TiO}_{2}$, and graphene increased the thermal stability of the silicone rubber continuously. An increase of 14 and $19^{\circ} \mathrm{C}$ in thermal stability was obtained for the S/MFS_10 and S/MFS_10/G2, respectively, which is linked to the physical interactions between the inclusion and matrix ${ }^{50}$. Stronger physical interaction between the $\mathrm{TiO}_{2}$ and silicone rubber matrix led to a significant increase in thermal stability with respect to its counterparts, where an increase of 34 and $42{ }^{\circ} \mathrm{C}$ in thermal stability of the composites was detected for the $\mathrm{S}_{/ T i O} \_20$ and $\mathrm{S}_{2} / \mathrm{TiO}_{2} \_20 / \mathrm{G} 2$, respectively ${ }^{20}$. Loading of $2 \mathrm{phr}$ graphene additive in $\mathrm{S} / \mathrm{TiO}_{2} \_20$ was resulted a significant increase in thermal stability of the rubber composite at $\mathrm{T}_{50 \%}$ with respect to its $\mathrm{S} / \mathrm{TiO}_{2} \_20$ corresponding composite $\left(\sim 40{ }^{\circ} \mathrm{C}\right)$. The addition of graphene additive to the S/MFS_10 or $\mathrm{S} / \mathrm{TiO}_{2} \_20$ composites was resulted in a higher maximum temperature decomposition with respect to the corresponding composites (see Table II). Derivative thermogravimetric (DTG) plots showed two steps weight-loss in all silicone rubber composites that will be further clarified with TGA-FTIR technique in the following. 

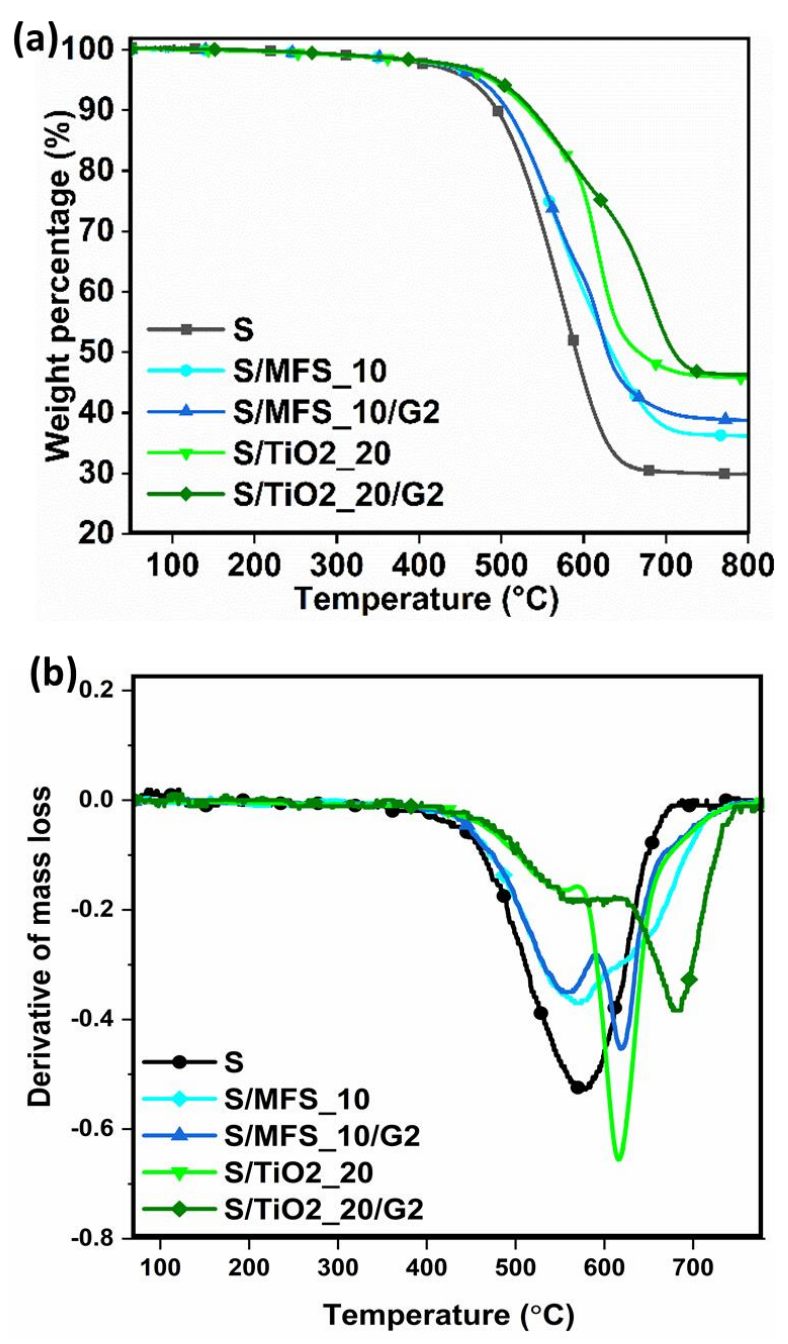

Fig. 7: TGA and DTG plots of silicone rubber and its composite over the range of temperatures from 50 to $800^{\circ} \mathrm{C}$.

Table II. TGA results of silicone rubber and its composites.

\begin{tabular}{lcccc}
\hline Sample & $\begin{array}{c}\mathrm{T}_{5 \%}\left({ }^{\circ} \mathrm{C}\right) \\
(\mathrm{T} \text { at } 5 \mathrm{wt} \% \\
\text { loss })\end{array}$ & $\begin{array}{c}\mathrm{T}_{50 \%}\left({ }^{\circ} \mathrm{C}\right) \\
(\mathrm{T} \text { at } 50 \mathrm{wt} \% \text { loss })\end{array}$ & $\mathrm{T}_{\text {max decomposition }}\left({ }^{\circ} \mathrm{C}\right)$ & $\begin{array}{c}\text { Residual mass } \\
\text { at } 800{ }^{\circ} \mathrm{C}(\mathrm{wt} \%)\end{array}$ \\
\hline $\mathrm{S}$ & 460 & 591 & 672 & 30 \\
S/MFS_10 & 474 & 629 & 680 & 36 \\
S/MFS_10/G2 & 479 & 632 & 683 & 39 \\
S/TiO 2 20 & 494 & 666 & 695 & 46 \\
S/TiO 2 20/G2 & 502 & 706 & 708 & 47 \\
\hline
\end{tabular}

To further investigate the thermal degradation mechanism of silicone rubber composites, TGA-FTIR spectroscopy was carried out and the 3-D thermograms (temperature-wavenumber-absorbance) are shown 
in Fig. 8. Several absorption peaks at $2960 \mathrm{~cm}^{-1}, 1260 \mathrm{~cm}^{-1}, 1070 \mathrm{~cm}^{-1}$ and $823 \mathrm{~cm}^{-1}$ related to cyclic oligomers were detected. In addition, an absorption peak at $3013 \mathrm{~cm}^{-1}$ was observed, which is related to the generated methane during the decomposition process. The volatile elements were detected, starting at 440 ${ }^{\circ} \mathrm{C}$ (showing as weight loss in TGA plots in Fig. 7), and the observed peaks in 3D map in Fig. 8. Thus, the degradation mechanism of the silicon atoms can be described by the fact that the silicone atoms initially were energized and favor to their vacant $3 \mathrm{~d}$ orbitals, and then form the cyclic oligomers and consequently deteriorating the polymer chain in which cause significant weight loss in the polymer. This significant weight loss was observed over the wavenumbers of 823 to $1260 \mathrm{~cm}^{-1} 51$. At high temperature (starting $550{ }^{\circ} \mathrm{C}$ ), the methyl groups were detached from the $\mathrm{S}$ rubber chains, converting to radical and ultimately, forming the methane molecules. Thus, the observed peak at $3013 \mathrm{~cm}^{-1}(\mathrm{C}-\mathrm{H}$ in methane) is related to the formation of methane molecules. 

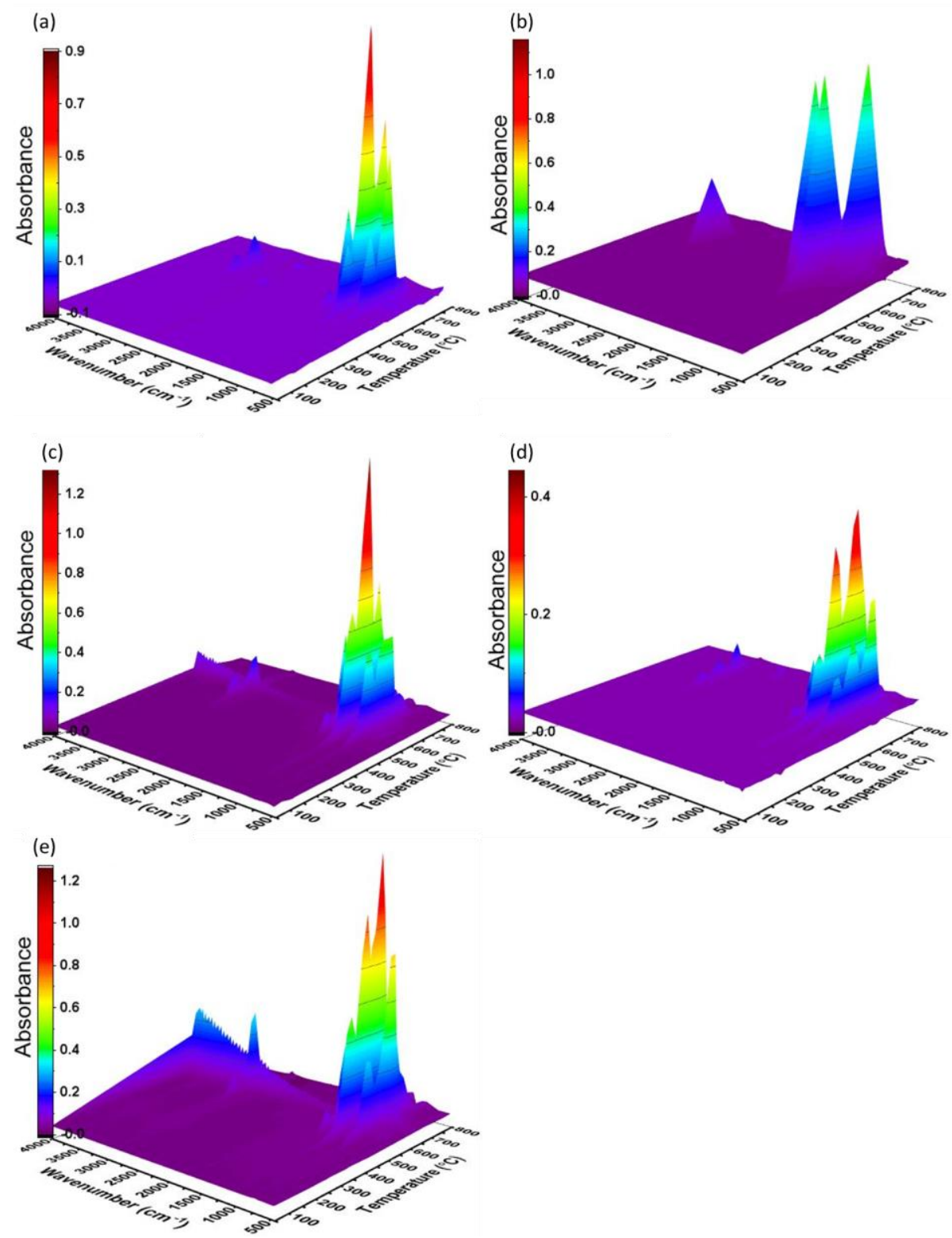

Fig. 8: The 3D maps of TGA-FTIR spectra of silicone rubber composites during pyrolysis for the (a) $\mathrm{S}$, (b) S/MFS_10, (c) S/MFS_10/G2, (d) $\mathrm{S} / \mathrm{TiO}_{2}-20$ and (e) $\mathrm{S} / \mathrm{TiO}_{2}-20 / \mathrm{G} 2$.

\subsection{Water contact angle}

To evaluate the hydrophobicity of silicone rubber composites, the static water contact angle was measured and the results are shown in Fig. 9. The average contact angle (ACA) and the standard deviation (SD) of the five measurements for each test specimen are shown below each sample. A relatively high static contact angle for silicone rubber was obtained $\left(\sim 108^{0}\right)$ which is linked to its low surface energy ${ }^{35}$. The addition of MFS led to a slight increase in contact angle $\left(6^{0}\right)$ which might be due to the higher surface roughness of the S/MFS_10 with respect to that of vulcanized silicone rubber. When 2 phr graphene was added to the 
former sample, the hydrophobicity was retained in the range of silicone rubber with no significant change. The addition of titanium dioxide to silicone rubber led to a reduction of hydrophobicity due to intrinsic hydrophilic properties of $\mathrm{TiO}_{2}$. Silicone rubber compounded with $\mathrm{TiO}_{2}$ and graphene was found to show a contact angle relatively close to silicone rubber.

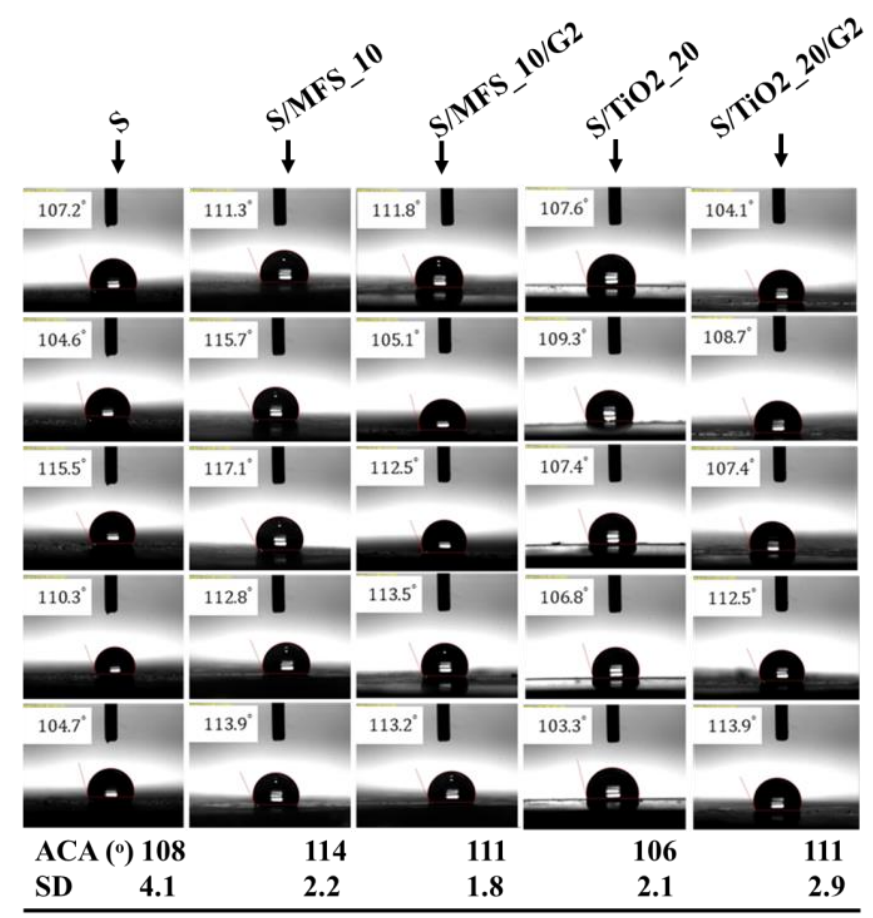

Fig. 9: Water contact angle of silicone rubber and its composite (average contact angle (ACA) and standard deviation (SD).

\subsection{Thermal conductivity}

Fig. 10 displays the thermal conductivity of the $\mathrm{S}$ rubber composites with $\mathrm{MFS}, \mathrm{TiO}_{2}$, and graphene. Several parameters such as the filler content, filler shape, particle size, the intrinsic thermal conductivity of the inclusions and the interfacial thermal resistance between the inclusions and matrix impact on thermal conductivity of the composites ${ }^{22,52,53}$. In addition, filler dispersion and distribution, filler treatment and compounding method can noticeably influence on thermal conductivity of the composites ${ }^{54}$. Graphene with its high thermal conductivity of $800 \mathrm{~W} / \mathrm{m} . \mathrm{K}$ is a promising filler to increase the thermal conductivity of composites ${ }^{54}$. The inorganic fillers $\left(\mathrm{MFS}\right.$ and $\mathrm{TiO}_{2}$ ) incorporated in $\mathrm{S}$ rubber were found to cause an increase in thermal conductivity mainly because of their intrinsic thermal conductivity being higher than the one of the matrix. The use of graphene results in a slight increase in the composites' thermal conductivity. Thus, the thermal conductivity of the composites at low filler contents is influenced by the interaction of filler-matrix and the interfacial thermal resistance (Fig. 11a), but when the content of the filler 
with a higher aspect ratio is increased, the thermal conductivity is determined by the filler network in which further facilitates the phonon transmission ${ }^{53}$ (see Fig. 11b).

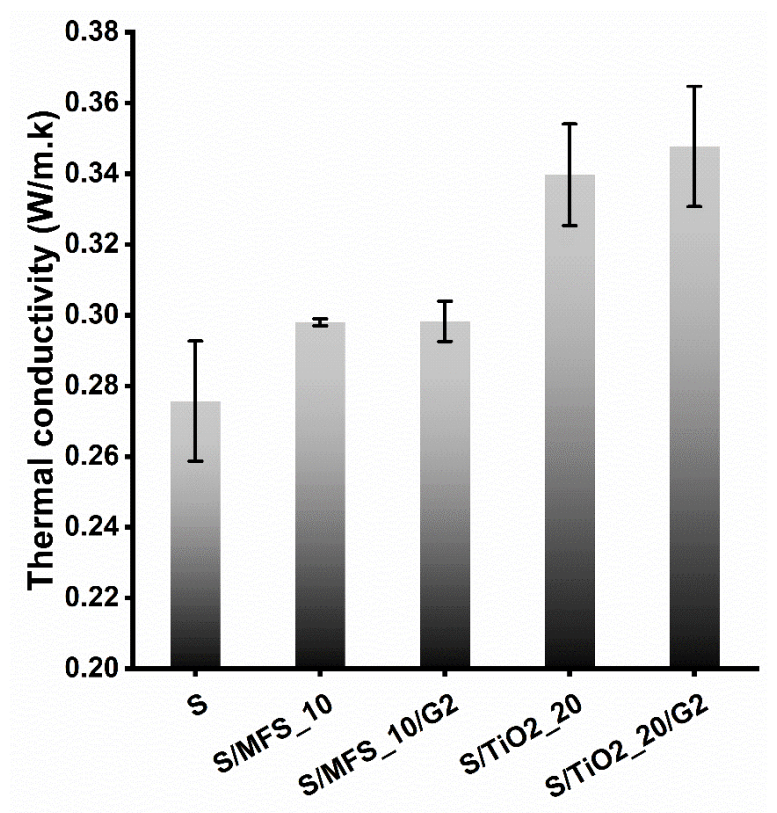

Fig. 10: Thermal conductivity of silicone rubber composites.
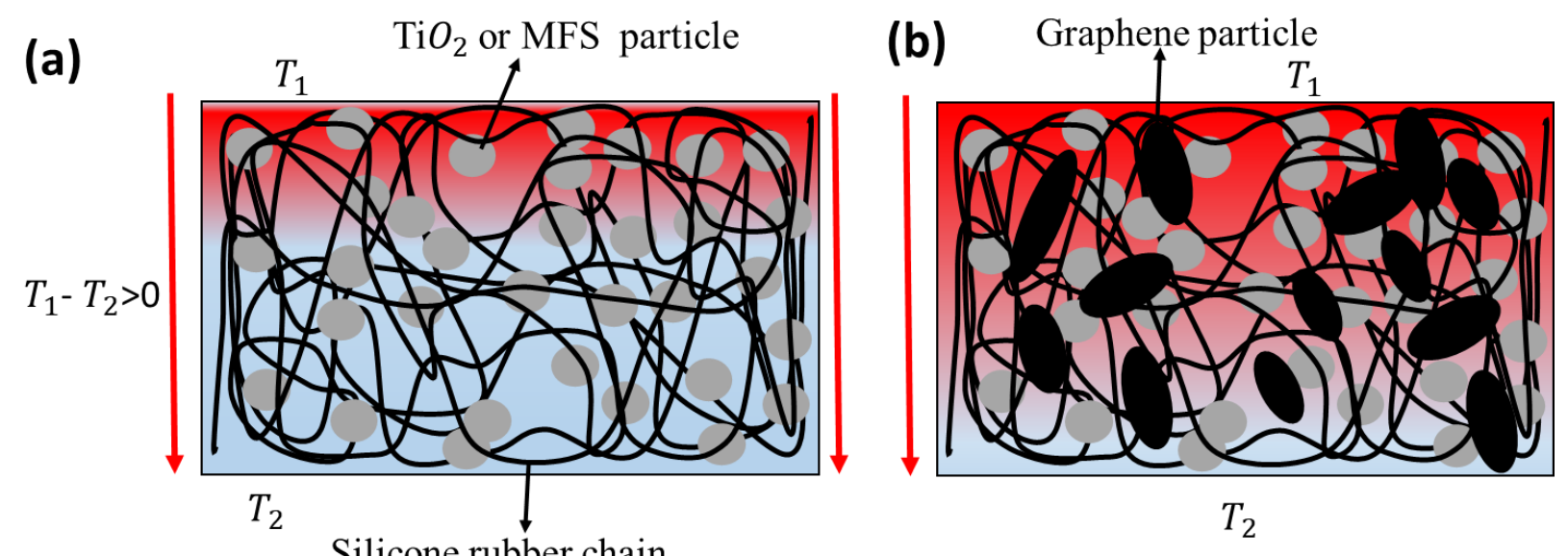

Fig. 11. The schematic of the thermal conduction in silicone rubber composite with (a) $\mathrm{TiO}_{2}$ or MFS and (b) $\mathrm{TiO}_{2}$ or MFS and graphene.

\section{Conclusions}

In this work, firstly, we have studied the role of MFS and $\mathrm{TiO}_{2}$ in the electrical and thermal properties of silicone rubber composites. Secondly, the co-combined composites with $2 \mathrm{phr}$ graphene filler were investigated and the results were compared. The addition of graphene filler was found to increase the 
thermal stability, dielectric constant and dielectric breakdown strength of the composites. On the other hand, no significant change in hydrophobicity, dielectric loss and thermal conductivity was observed. Though, the MFS and $\mathrm{TiO}_{2}$ additives were found to have some physical interactions with the host rubber, no chemical interaction was seen between filler and matrix by FTIR spectroscopy. The improvement in electrical and thermal performance of the black rubber composites with MFS and $\mathrm{TiO}_{2}$ can withstand longer against UV protection that gives another positive property for the use in outdoor insulating applications. In comparison, $\mathrm{S}$ rubber composites including $\mathrm{TiO}_{2}$ featured higher dielectric constant, thermal conductivity, AC breakdown strength as well higher thermal stability.

\section{Acknowledgment}

The authors would like to thank Mrs. Vazirinasab, Dr. Nima Moghimian and Dr. Seyed Milad Madinehei for their kind collaboration, as well as support by Natural Sciences and Engineering Research Council of Canada.

\section{References}

1. Lin, Y.; Wang, L.; Yin, F.; Farzaneh, M.; Liu, Y.; Gao, S., J. Appl. Polym. Sci., 47477 2019.

2. Zhu, Y., Polym. Test. 74, 142019.

3. Cherney, E. A., IEEE Transactions on Dielectrics and Electrical Insulation 12, 11082005.

4. Yan, F.; Zhang, X.; Liu, F.; Li, X.; Zhang, Z., Composites Part B: Engineering 75, 472015.

5. Youn, B.-H.; Huh, C.-S., IEEE Transactions on Dielectrics and Electrical Insulation 12, 10152005.

6. $\quad$ Kim, E. S.; Kim, E. J.; Shim, J. H.; Yoon, J. S. J. J. o. a. p. s., 110, 12632008.

7. Yang, D.; Zhang, W.; Yao, R.; Jiang, B., Polym. Degrad. Stab. 98, 1092013.

8. Vazirinasab, E.; Jafari, R.; Momen, G., Surf. Coat. Technol. 341, 402018.

9. Xue, Y.; Li, X.-f.; Zhang, D.-h.; Wang, H.-s.; Chen, Y.; Chen, Y.-f., Compos. Sci. Technol. 155, 1372018.

10. Azizi, S.; Momen, G.; Ouellet-Plamondon, C.; David, E., Polym. Test. 84, 1062812020.

11. Zhu, Y.; Otsubo, M.; Honda, C.; Ohno, A., Polym. Test. 24, 8932005.

12. Paredes, M.; Angammana, C. J.; Jayaram, S. H. 2016 IEEE Conference on Electrical Insulation and Dielectric Phenomena (CEIDP), 2016, pp 683.

13. Chen, D.; Liu, Y.; Huang, C., Polym. Degrad. Stab. 97, 3082012.

14. Pallon, L.; Hoang, A.; Pourrahimi, A.; Hedenqvist, M. S.; Nilsson, F.; Gubanski, S.; Gedde, U.; Olsson, R. T., Journal of Materials Chemistry A 4, 85902016.

15. Wu, C.; Liang, X.; Dissado, L. A.; Chalashkanov, N. M.; Dodd, S. J.; Gao, Y.; Xu, S., Compos. Sci. Technol. 163, 562018.

16. Métivier, T.; Cassagnau, P., Polymer2018. 
17. Klonos, P.; Bolbukh, Y.; Koutsiara, C.; Zafeiris, K.; Kalogeri, O.; Sternik, D.; DeryłoMarczewska, A.; Tertykh, V.; Pissis, P., Polymer 148, 12018.

18. Bleszynski, M.; Kumosa, M., Compos. Sci. Technol. 164, 742018.

19. Nazir, M. T.; Phung, B.; Hoffman, M.; Yu, S.; Li, S., Mater. Lett. 209, 4212017.

20. Dang, Z.-M.; Xia, Y.-J.; Zha, J.-W.; Yuan, J.-K.; Bai, J., Mater. Lett. 65, 34302011.

21. Azizi, M.; Zolfaghari Sharak, A.; Mousavi, S. A.; Bakhtiari Ziabari, F.; Shariati, J.; Azizi, S., Chem. Eng. Commun. 200, 8632013.

22. Zha, J.-W.; Zhu, Y.-H.; Li, W.-K.; Bai, J.; Dang, Z.-M., Appl. Phys. Lett. 101, 062905 2012.

23. Li, X.; Zhang, D.; Chen, Y., Mater. Lett. 205, 2402017.

24. Liu, D.; Pourrahimi, A. M.; Olsson, R. T.; Hedenqvist, M.; Gedde, U., Eur. Polym. J. 66, 672015.

25. Pourrahimi, A. M.; Olsson, R. T.; Hedenqvist, M. S., Adv. Mater. Processes 30, 1703624 2018.

26. Akhlaghi, S.; Pourrahimi, A.; Sjöstedt, C.; Bellander, M.; Hedenqvist, M.; Gedde, U., Polym. Degrad. Stab. 138, 272017.

27. Azizi, S.; David, E.; Fréchette, M. F.; Nguyen-Tri, P.; Ouellet-Plamondon, C., Polym. Test.2018.

28. Azizi, S.; Ouellet-Plamondon, C.; David, E.; Fréchette, M., IEEE2018.

29. Gan, L.; Shang, S.; Yuen, C. W. M.; Jiang, S.-x.; Luo, N. M., Composites Part B: Engineering 69, 2372015.

30. Emelyanenko, A. M.; Boinovich, L. B.; Bezdomnikov, A. A.; Chulkova, E. V.; Emelyanenko, K. A., ACS applied materials \& interfaces 9, 242102017.

31. Vazirinasab, E.; Jafari, R.; Momen, G. J. S.; Technology, C., 341, 402018.

32. Dimitropoulou, M.; Pylarinos, D.; Siderakis, K.; Thalassinakis, E.; Danikas, M., Engineering, Technology \& Applied Science Research 5, 7642015.

33. Kashani, M. R.; Javadi, S.; Gharavi, N., Smart Mater. Struct. 19, 0350192010.

34. Paul, D. R.; Mark, J. E., Prog. Polym. Sci. 35, 8932010.

35. Momen, G.; Farzaneh, M., Rev. Adv. Mater. Sci 27, 12011.

36. Zhang, Y.; Zeng, X.; Lai, X.; Li, H.; Huang, X., Polym. Test. 69, 162018.

37. Song, Y.; Yu, J.; Yu, L.; Alam, F. E.; Dai, W.; Li, C.; Jiang, N., Materials \& Design 88, 9502015.

38. Wang, Z.; Nelson, J.; Hillborg, H.; Zhao, S.; Schadler, L. 2012 Annual Report Conference on Electrical Insulation and Dielectric Phenomena, 2012, pp 40.

39. Nguyen, D.; Sylvestre, A.; Gonon, P.; Rowe, S. Proceedings of the 2004 IEEE International Conference on Solid Dielectrics, 2004. ICSD 2004., 2004, pp 103.

40. Azizi, S.; Ouellet-Plamondon, C.; Tri, P. N.; Fréchette, M.; David, E., Composites Part B: Engineering, 1072882019.

41. Azizi, S.; David, É.; Fréchette, M. F.; Ouellet-Plamondon, C. M., IET Nanodielectrics2019. 
42. Yu, L.; Skov, A. L. J. I. J. o. S.; Materials, N., 6, 2682015.

43. Anh, T. T.; Fréchette, M.; David, É.; Veillette, R.; Moraille, P., J. Appl. Polym. Sci. 135, 460952018.

44. Azizi, S.; Azizi, M.; Sabetzadeh, M., Journal of Composites Science 3, 642019.

45. Azizi, S.; Ouellet-Plamondon, C.; David, E.; Fréchette, M. Electrical Insulation and Dielectric Phenomenon (CEIDP), 2017 IEEE Conference on, 2017, pp 517.

46. Liu, D.; Hoang, A.; Pourrahimi, A. M.; Pallon, L. H.; Nilsson, F.; Gubanski, S.; Olsson, R. T.; Hedenqvist, M. S.; Gedde, U. W.; Insulation, E., IEEE Transactions on Dielectrics 24, 1396 2017.

47. Wu, T.; Lai, X.; Liu, F.; Li, H.; Zeng, X., Appl. Surf. Sci. 459, 4832018.

48. Akhlaghi, S.; Pourrahimi, A. M.; Sjostedt, C.; Bellander, M.; Hedenqvist, M. S.; Gedde, U. W., Polym. Degrad. Stab. 136, 102017.

49. Su, M.; Zeng, X.; Lai, X.; Li, H., Polym. Test. 65, 4912018.

50. $\quad$ Gan, L.; Shang, S.; Jiang, S.-X., Composites Part B: Engineering 84, 2942016.

51. Tomer, N. S.; Delor-Jestin, F.; Frezet, L.; Lacoste, J. J. O. J. o. O. P. M., 2, 132012.

52. Azizi, S.; David, E.; Fréchette, M. F.; Nguyen-Tri, P.; Ouellet-Plamondon, C. M., J. Appl. Polym. Sci., 470432018.

53. Huang, C. L.; Qian, X.; Yang, R. G., Materials Science \& Engineering R-Reports 132, 1 2018.

54. Han, Z.; Fina, A., Prog. Polym. Sci. 36, 9142011. 